\title{
Knowledge, Attitude, and Perceived Mental Healthcare Needs of Turkish Dentistry Students Regarding the COVID-19 Pandemic
}

\author{
Nurcan Altas ${ }^{1}$, Zeynep C Yilmaz ${ }^{2}$
}

\begin{abstract}
Aim and objective: An outbreak can only be prevented if people have adequate knowledge regarding the disease, are aware of the possible risks, and alter their attitudes and behaviors accordingly. This study aimed to investigate the knowledge and attitudes regarding coronavirus disease-2019 (COVID-19), as well as the concerns and perceived mental healthcare needs, among dentistry students.

Materials and methods: A questionnaire was completed by 4th- and 5th-year dental students. Part 1 included items regarding the students' characteristics and concerns. Parts 2,3, and 4 contained items regarding the students' knowledge, attitudes, and perceived mental healthcare needs about COVID-19.

Results: This study included 224 students. They indicated a moderate knowledge level $(7.35 \pm 1.26)$, positive attitude score (42.98 \pm 2.96$)$, and high perceived mental healthcare needs $(3.31 \pm 0.97)$. Most students were aware of the source $(89.7 \%)$, transmission route $(99.1 \%)$, and incubation period (98.21\%). Further, 4th-year students were significantly more worried than 5 th-year students that the pandemic would affect their medical skills.

Conclusion: Our findings revealed deficiencies in knowledge regarding COVID-19 among dentistry students. Therefore, there is a need to increase knowledge about COVID-19 among studies. Moreover, universities and governments should search for new channels for students' concerns and mental healthcare needs.

Clinical significance: There is a need to increase knowledge about COVID-19 among studies through several means, including lessons, and universities and governments should search for new channels for students' concerns and mental healthcare needs.

Keywords: COVID-19, Dental students, Knowledge.

International Journal of Experimental Dental Science (2020): 10.5005/jp-journals-10029-1210
\end{abstract}

\section{INTRODUCTION}

Severe acute respiratory syndrome (SARS) coronavirus 2 is a novel coronavirus strain that was first diagnosed in Wuhan, China, as a cluster of pneumonia cases in December 2019. On January 30, 2020, the World Health Organization (WHO) announced it as a major public health issue and subsequently as an epidemic. ${ }^{1}$ On March 11, coronavirus disease-2019 (COVID-19) was declared as a pandemic and as of November 25, there have been $60,349,260$ laboratory-confirmed cases and 1,419,296 deaths. ${ }^{2}$ Controlling its spread to reduce the burden on the healthcare system is among the main concerns of governments.

Given the strong human-to-human COVID-19 transmission rate, the cross-infection risk may be high among dental practitioners, dental students, and patients. To lower this risk, dental offices and universities require strict and effective infection-control protocols. The Centers for Disease Control and Prevention (CDC) and WHO have published several guidelines regarding standardized preventive methods for healthcare workers. ${ }^{3,4}$

To address this pandemic, there is a need for medical staff adherence to guidelines, which is largely dependent on their knowledge, attitudes, and practices (KAP) toward COVID-19 according to the KAP theory., ${ }^{5,6}$ After experiencing the SARS outbreak in 2003, there is an association of knowledge and attitudes toward infectious diseases with the panic emotion level in the population, which further complicates the disease prevention protocol. ${ }^{7}$

Previous studies have evaluated the level of knowledge, attitude, and behavior of dentists and dental students with respect
${ }^{1}$ Department of Periodontology, Istanbul Medipol University, Esenler, İstanbul, Turkey

${ }^{2}$ Department of Oral and Maxillofacial Surgery, Istanbul Medipol University, Esenler, İstanbul, Turkey

Corresponding Author: Zeynep C Yilmaz, Department of Oral and Maxillofacial Surgery, Istanbul Medipol University, Esenler, İstanbul, Turkey, Phone: +90-212-440-10-00, e-mail: zeynepcukurova@gmail. com

How to cite this article: Altas N, Yilmaz ZC. Knowledge, Attitude, and Perceived Mental Healthcare Needs of Turkish Dentistry Students Regarding the COVID-19 Pandemic. Int J Experiment Dent Sci 2020;9(2):31-37.

Source of support: Nil

Conflict of interest: None

to infection-control guidelines and precautions. ${ }^{8,9}$ These studies emphasized the need to further develop such information in practical life. Dentists play a crucial role in preventing COVID-19 transmission during dental procedures. Further, given that they are mostly exposed to body fluids, including blood, saliva, and multifarious aerosols/droplets, there is a great virus transmission risk among dental healthcare professionals. ${ }^{10}$ The virus has been detected in the saliva of infected patients and it spreads via droplets. ${ }^{11}$ A clinical study by Chen et al. ${ }^{12}$ reported that $29 \%$ of 138 patients with COVID-19 hospitalized in Wuhan, China, were healthcare professionals. 
There is limited evidence regarding attitudes and knowledge among dentistry students toward infection-control measures in operative settings. Outbreaks significantly affect psychological well-being; further, they may cause psychological stress, which negatively affects learning and the overall psychological health of students, but so far, the effects of quarantine have not been assessed. ${ }^{13,14}$ Currently, there has been no study on the perceived mental healthcare needs of dentistry students. The media has significantly contributed to increasing mental distress; ${ }^{14}$ moreover, the distress rate among dental staff is higher than that in the general population. This study aimed to investigate the general knowledge and attitudes regarding COVID-19 infection among 4th- and 5th-year dental students to allow more effective health education for preventing spread during the outbreak in Istanbul, Turkey. Moreover, this study aimed to identify dental students' psychological needs during the COVID-19 outbreak. This study is unique given that it seeks to demonstrate the early psychological impact of COVID-19 according to the mental healthcare needs of dental students with respect to their professional and daily lives during the quarantine period.

\section{Materials and Methods}

\section{Study Design and Participants}

This descriptive cross-sectional study was performed in a private dentistry faculty in Istanbul between May and June 2020. The study was approved by the Ethical Committee of Istanbul Medipol University of Medical Sciences (Protocol number: 10840098604.01.01-E.14937). We enrolled 4th-and 5th-year dental students in clinical rotation.

\section{Sample Size Calculation}

The sample size was calculated using the $G^{*}$ power statistical power analysis 3.1 program. Considering an alpha of 0.05 , a power of 0.80 , and an effect size of $\rho=0.12$, the calculated sample size was 158 participants. To account for individuals who did not want to participate, a questionnaire was sent to 296 4th-and 5th-year undergraduate students. Subsequently, 224 responses were received and included in the study.

\section{Data Collection}

The questionnaire was prepared based on detailed literature and internationally accepted guidelines. ${ }^{15-17}$ Data were collected using an anonymous online survey (Google Forms) to prevent transmission during the pandemic, ensure the participants' privacy, and allow faster data collection. The questionnaire was sent to five professional lecturers (two oral and maxillofacial surgeons, one periodontist, one anesthesiologist, and one otolaryngologist) with their opinions being evaluated and the questions being modified accordingly. Further, a pilot survey was administered to 10 dental students to assess the questionnaire's reliability. An adequate Cronbach's alpha of 0.71 was obtained and final e-survey forms were sent to students via a link explaining the questionnaire purpose. Subsequently, data collection was performed for research purposes.

\section{Questionnaire Content}

The questionnaire comprised of four parts. The first part collected the students' demographic data, including their age, gender, information source, and future work-life concerns. The respondents' characteristics were assessed using open-ended questions. The second and third parts contained questions regarding the knowledge level and attitudes on COVID-19 infection. The final part included questions about the perceived mental healthcare needs.

The second part comprised 10 multiple-choice questions regarding the knowledge level with each correct and incorrect answer being assigned 1 and 0 points, respectively (range of the knowledge score: $0-10$ ). Based on Bloom's cut-off points, scores $\geq 8,5-7$, and $<5$ indicate good, moderate, and poor knowledge levels, respectively. Moreover, there were 10 questions evaluating attitude using a five-grade Likert-type scale. This scale was used to express the intensity of patients' opinions more accurately. For each question, 1, 2, 3, 4, and 5 points were assigned to strongly disagree, disagree, undecided, agree, and strongly agree, respectively. The attitude was considered positive, neutral, and negative if the mean score was $\geq 40,25-39$, and $<25$, respectively. The questions about knowledge and attitude are adopted from the study by Althomairy et al. ${ }^{18}$

To evaluate perceived mental healthcare needs for COVID-19, we used four yes/no questions adopted from the study by Roy et al. ${ }^{19} \mathrm{~A}$ score $\geq 3$ was indicative of a high mental healthcare need.

\section{Data Analysis}

Statistical analyzes were performed using the NCSS (Number Cruncher Statistical System) 2007 Statistical Software (Utah, USA) package program. In addition to descriptive statistics (mean, standard deviation, frequency, and percentage distributions), the distribution of variables was examined using the Shapiro-Wilk normality test. Moreover, an independent $t$-test and the Chi-square test were used for comparisons of normally distributed variables and qualitative data, respectively. Statistical significance was set at $p<0.05$.

\section{Results}

\section{Demographic Data and Concerns about Future}

Table 1 presents the demographic characteristics of the students. There were 224 responses (response rate: $75.68 \%$ ). The mean age of the responders was $23.49 \pm 1.24$ years (age range: $21-28$ years) with most being female (143, 63.84\%). Further, $93.3 \%$ reported lacking any chronic condition while $81.7 \%$ were nonsmokers. The main sources of information on COVID-19 were social media $(56.3 \%)$, followed by television or radio (38.4\%), social circle (3.1\%), and family (1.3\%).

The participants were asked whether they were worried about their education quality and medical skills. Furthermore, they were asked questions regarding their economic concerns and job opportunities after the COVID-19 pandemic (Table 2). The participants mostly (25.9\% strongly agree, $31.2 \%$ agree) considered that their medical skills would be negatively affected due to interrupted patient admission during their education. However, there was a significant difference in the answer distributions of 4 th- and 5th-year students $(p=0.0001)$. Specifically, there were more 5th-year students (32.22\%) with "Absolutely Disagree,

Table 1: Distribution of participants based on their characteristics

\begin{tabular}{lll}
\hline & \multicolumn{2}{c}{ Student distribution } \\
\cline { 2 - 3 } Characteristics & & $n(\%)$ \\
\hline Year & 4 th & $134(59.82)$ \\
\multirow{2}{*}{ Gender } & 5 th & $90(40.18)$ \\
& Male & $81(36.16)$ \\
& Female & $143(63.84)$ \\
\hline
\end{tabular}


Table 2: Concerns of dentistry students regarding their work and life

\begin{tabular}{|c|c|c|c|c|c|c|c|c|}
\hline \multirow{2}{*}{ Items } & & \multicolumn{6}{|c|}{ Answers N (\%) } & \multirow[b]{2}{*}{$p$} \\
\hline & & $S A$ & \multicolumn{2}{|l|}{$A$} & $U$ & $D$ & $S D$ & \\
\hline \multicolumn{2}{|c|}{$\begin{array}{l}\text { I think my dental practice will be insufficient when I graduate or } \\
\text { become a 5th-year student, and that the COVID-19 pandemic will } \\
\text { concomitantly affect my medical skills. }\end{array}$} & $58(25.9)$ & $70(31.2)$ & \multicolumn{2}{|r|}{$50(22.3)$} & $38(17)$ & $8(3.6)$ & $0.0001^{a}$ \\
\hline \multicolumn{2}{|l|}{$\begin{array}{l}\text { I think dental treatment prices will increase after the COVID-19 } \\
\text { pandemic. }\end{array}$} & $36(16.1)$ & \multicolumn{2}{|c|}{$74(33)$} & $77(34.4)$ & $32(14.3)$ & $5(2.2)$ & 0.053 \\
\hline \multicolumn{2}{|l|}{$\begin{array}{l}\text { I think dentists will experience reduced job opportunities after } \\
\text { the COVID-19 outbreak. }\end{array}$} & $26(11.6)$ & \multicolumn{2}{|c|}{$68(30.4)$} & $61(27.2)$ & $63(28.1)$ & $6(2.7)$ & 0.068 \\
\hline \multicolumn{9}{|c|}{$\begin{array}{l}p \text { values show differences between groups. Chi-squared test; SA, strongly agre } \\
{ }^{\mathrm{a}} p<0.01, \chi^{2} \text { test }\end{array}$} \\
\hline \multicolumn{2}{|l|}{ Questions } & \multicolumn{2}{|c|}{ Total \% } & \multicolumn{2}{|r|}{ 4th year } & \multicolumn{2}{|r|}{ 5th year } & $p$ \\
\hline \multirow[t]{2}{*}{ 1. The main source of COVID-19 } & Wrong & 23 & 10.27 & 14 & 10.45 & 9 & 10.00 & 0.914 \\
\hline & Right & 201 & 89.73 & 120 & 89.55 & 81 & 90.00 & \\
\hline \multirow[t]{2}{*}{ 2. Means of transmission of COVID-19 } & Wrong & 2 & 0.89 & 1 & 0.75 & 1 & 1.11 & 0.776 \\
\hline & Right & 222 & 99.11 & 133 & 99.25 & 89 & 98.89 & \\
\hline \multirow[t]{2}{*}{ 3. The main symptoms of COVID-19 } & Wrong & 68 & 30.36 & 36 & 26.87 & 32 & 35.56 & 0.166 \\
\hline & Right & 156 & 69.64 & 98 & 73.13 & 58 & 64.44 & \\
\hline \multirow[t]{2}{*}{ 4. Incubation time } & Wrong & 4 & 1.79 & 4 & 2.99 & 0 & 0.00 & 0.098 \\
\hline & Right & 220 & 98.21 & 130 & 97.01 & 90 & 100.00 & \\
\hline 5. Methods for prevention against COVID-19 infection & Wrong & 26 & 11.61 & 14 & 10.45 & 12 & 13.33 & 0.509 \\
\hline & Right & 198 & 88.39 & 120 & 89.55 & 78 & 86.67 & \\
\hline 6. Type of COVID-19 virus & Wrong & 154 & 68.75 & 102 & 76.12 & 52 & 57.78 & $0.004^{\mathrm{a}}$ \\
\hline & Right & 70 & 31.25 & 32 & 23.88 & 38 & 42.22 & \\
\hline 7. Mortality rate of patients with COVID-19 & Right & 224 & 100.00 & 134 & 100.00 & 90 & 100.00 & NA \\
\hline 8. Mortality rate of patients with COVID-19 with comorbid & Wrong & 124 & 55.36 & 79 & 58.96 & 45 & 50.00 & 0.186 \\
\hline & Right & 100 & 44.64 & 55 & 41.04 & 45 & 50.00 & \\
\hline 9. Rate of asymptomatic cases & Wrong & 113 & 50.45 & 73 & 54.48 & 40 & 44.44 & 0.141 \\
\hline & Right & 111 & 49.55 & 61 & 45.52 & 50 & 55.56 & \\
\hline 10. Treatment of COVID-19 & Wrong & 80 & 35.71 & 50 & 37.31 & 30 & 33.33 & 0.542 \\
\hline & Right & 144 & 64.29 & 84 & 62.69 & 60 & 66.67 & \\
\hline
\end{tabular}

$p$ values show differences between groups

${ }^{a} p<0.01, \chi^{2}$ test

Disagree" answers than 4th-year students (12.69\%). Additionally, $34 \%$ of the responders were indecisive regarding the effect of the pandemic on dental treatment prices. There was no significant difference between responders who thought that the pandemic would significantly decrease and not affect their job opportunities.

\section{COVID-19 Knowledge and Attitudes of Students}

Table 3 presents the knowledge level of COVID-19 among the dentistry students. Questions 8 and 7 had the lowest (44.6\%) and highest (100\%) percentage of correct answers, respectively. Most of the participants correctly identified hallmark 3 symptoms (69.6\%); further, $88.39 \%$ of the participants knew how to prevent infection. There was a high knowledge level regarding the source, transmission, and incubation period of the disease among 4th- and 5th-year students. The only between-year difference in knowledge was observed only in the sixth question, which was COVID-19 virus is the same as the SARS and MERS-CoV viruses; specifically, 5th-year students had a significantly higher proportion of correct answers to this question $(p=0.004)$.
Table 4 shows the attitudes toward the airborne/droplet precaution and protections. There was no significant difference between years in the total attitude score. The lowest and highest scores were observed for question 2 and questions 6-7, respectively. All the participants agreed that personal protective equipment should be worn and that healthcare workers should be acknowledged before dental treatment. Among the students, $86.2 \%$ preferred performing only dental emergency procedures. Regarding aerosol-generating procedures, $88 \%$ of the students stated that they did not require additional precautions during dental treatments. Further, $98.7 \%$ of the participants indicated that individuals exposed to a patient with COVID-19 should be isolated for 14 days.

\section{Perceived Mental Healthcare Needs}

Regarding the perceived mental healthcare needs among participants, there was no significance between-year difference in all the questions on concerns about the COVID-19 outbreak. Most participants (91.1\%) thought that it would be beneficial if mental healthcare professionals helped individuals to deal with the COVID- 
Table 4: Attitude among dentistry students toward airborne and droplet precaution and protections from COVID-19 infection

\begin{tabular}{|c|c|c|c|c|c|c|c|c|}
\hline Questions & & & Total & & 4th year & & 5th year & $p$ \\
\hline \multirow{3}{*}{$\begin{array}{l}\text { 1. COVID-19 transmission can be prevented using universal } \\
\text { precautions given by CDC, WHO, etc. }\end{array}$} & $\mathrm{SA}, \mathrm{A}$ & 159 & $70.98 \%$ & 96 & $71.64 \%$ & 63 & $70.00 \%$ & 0.964 \\
\hline & U & 46 & $20.54 \%$ & 27 & $20.15 \%$ & 19 & $21.11 \%$ & \\
\hline & $D, S D$ & 19 & $8.48 \%$ & 11 & $8.21 \%$ & 8 & $8.89 \%$ & \\
\hline \multirow{3}{*}{$\begin{array}{l}\text { 2. The prevalence of COVID-19 can be reduced by the active } \\
\text { participation of healthcare workers in hospital infection- } \\
\text { control programs }\end{array}$} & $\mathrm{SA}, \mathrm{A}$ & 146 & $65.18 \%$ & 86 & $64.18 \%$ & 60 & $66.67 \%$ & 0.904 \\
\hline & U & 56 & $25.00 \%$ & 34 & $25.37 \%$ & 22 & $24.44 \%$ & \\
\hline & $D, S D$ & 22 & $9.82 \%$ & 14 & $10.45 \%$ & 8 & $8.89 \%$ & \\
\hline \multirow{3}{*}{$\begin{array}{l}\text { 3. Related information about COVID-19 should be } \\
\text { disseminated among dentistry students }\end{array}$} & $\mathrm{SA}, \mathrm{A}$ & 218 & $97.32 \%$ & 128 & $95.52 \%$ & 90 & $100.00 \%$ & 0.126 \\
\hline & U & 4 & $1.79 \%$ & 4 & $2.99 \%$ & 0 & $0.00 \%$ & \\
\hline & $D, S D$ & 2 & $0.89 \%$ & 2 & $1.49 \%$ & 0 & $0.00 \%$ & \\
\hline \multirow{3}{*}{$\begin{array}{l}\text { 4. Patients with COVID-19 should be kept in isolation for } 14 \\
\text { days }\end{array}$} & $\mathrm{SA}, \mathrm{A}$ & 221 & $98.66 \%$ & 131 & $97.76 \%$ & 90 & $100.00 \%$ & 0.360 \\
\hline & U & 2 & $0.89 \%$ & 2 & $1.49 \%$ & 0 & $0.00 \%$ & \\
\hline & $D, S D$ & 1 & $0.45 \%$ & 1 & $0.75 \%$ & 0 & $0.00 \%$ & \\
\hline \multirow{3}{*}{$\begin{array}{l}\text { 5. Emergency treatment should be applied only to patients } \\
\text { diagnosed with COVID-19 }\end{array}$} & $\mathrm{SA}, \mathrm{A}$ & 193 & $86.16 \%$ & 117 & $87.31 \%$ & 76 & $84.44 \%$ & 0.517 \\
\hline & U & 14 & $6.25 \%$ & 9 & $6.72 \%$ & 5 & $5.56 \%$ & \\
\hline & $D, S D$ & 17 & $7.9 \%$ & 8 & $5.97 \%$ & 9 & $10.00 \%$ & \\
\hline $\begin{array}{l}\text { 6. Healthcare workers must update themselves on all the } \\
\text { information about COVID-19 }\end{array}$ & SA, A & 224 & $100.00 \%$ & 134 & $100.00 \%$ & 90 & $100.00 \%$ & NA \\
\hline $\begin{array}{l}\text { 7. Personal protective equipment, including gowns, } \\
\text { gloves, surgical masks, and googles, must be used when } \\
\text { handling patients with COVID-19 }\end{array}$ & $\mathrm{SA}, \mathrm{A}$ & 224 & $100.00 \%$ & 134 & $100.00 \%$ & 90 & $100.00 \%$ & NA \\
\hline \multirow{2}{*}{$\begin{array}{l}\text { 8. Before dental treatment, dental professionals should be } \\
\text { informed about the positive diagnosis of the patient. } \\
\text { Accordingly, they should take preventive measures } \\
\text { before the patient arrives }\end{array}$} & $\mathrm{SA}, \mathrm{A}$ & 221 & $98.66 \%$ & 132 & $98.51 \%$ & 89 & $98.89 \%$ & 0.808 \\
\hline & U & 3 & $1.34 \%$ & 2 & $1.49 \%$ & 1 & $1.11 \%$ & \\
\hline \multirow{2}{*}{$\begin{array}{l}\text { 9. Dentists and dental assistants should apply hand } \\
\text { hygiene using alcohol-based sanitizers, as well as soap } \\
\text { and water }\end{array}$} & $\mathrm{SA}, \mathrm{A}$ & 223 & $99.55 \%$ & 133 & $99.25 \%$ & 90 & $100.00 \%$ & 0.411 \\
\hline & U & 1 & $0.45 \%$ & 1 & $0.75 \%$ & 0 & $0.00 \%$ & \\
\hline \multirow{3}{*}{$\begin{array}{l}\text { 10. Additional precautions are not required when perform- } \\
\text { ing aerosol-generating procedures }\end{array}$} & $S A, A$ & 197 & $87.95 \%$ & 115 & $85.82 \%$ & 82 & $91.11 \%$ & 0.074 \\
\hline & U & 18 & $8.04 \%$ & 15 & $11.19 \%$ & 3 & $3.33 \%$ & \\
\hline & $D, S D$ & 9 & $4.02 \%$ & 4 & $2.99 \%$ & 5 & $5.56 \%$ & \\
\hline
\end{tabular}

$p$ values show differences between groups. $\chi^{2}$ test; $S A$, strongly agree; $A$, agree; $U$, undecided; $D$, disagree; $S D$, strongly disagree

19 pandemic situation (Table 5). The first question had the lowest score, with $32.6 \%$ of the participants stating that they did not want to talk about their worries about the pandemic.

The total mean scores for knowledge, attitude, and mental healthcare needs were $7.35 \pm 1.26,42.98 \pm 2.96$, and $3.31 \pm 0.97$, respectively (Table 6). This suggested that the students had a moderate knowledge level, positive attitude, and a high need for mental health care. There was no significant between-year difference in the total score averages.

\section{Discussion}

On March 11, 2020, the first COVID-19 case was diagnosed and announced in Turkey. After 1 week, all universities were closed until the completion of the school term and switched to online education. Since the virus is transmitted by direct contact or aerosol/droplet inhalation during dental procedures, we enrolled 4th- and 5th-year dental students who worked in close contact with patients in our study.

We found that most of the students obtained information about COVID-19 online, which is consistent with the finding by Khan et al. ${ }^{20}$ that health workers mostly obtained information about MERS-CoV from the Internet. Given the widespread Internet usage among individuals aged 16-24 years in Turkey, the Internet is the most common means of accessing information in this age range, which is consistent with our findings. ${ }^{21}$ In our study, television and radio were the second most common information sources.

The COVID-19 infection and spread rate are higher than that of other known viral infections; moreover, it has currently caused $>13,000$ deaths in Turkey. ${ }^{22}$ Therefore, health behaviors and knowledge levels among health workers are crucial for lowering the infection rate and fatalities.

Although dentistry is among the highest-risk groups for COVID-19 infection, few studies have evaluated the knowledge and attitudes regarding COVID-19 among dental students. This study assessed dental students' worries regarding their academic performance and clinical competence, knowledge levels, attitude, and perceived mental healthcare needs.

In our study, the students exhibited moderate knowledge levels and positive attitudes $(7.35 \pm 1.26$ and $42.98 \pm 2.96$, respectively). Inconsistent with these findings, Esmaeelinejad et al. ${ }^{23}$ reported an inadequate $(59.7 \%)$ and low (66\%) knowledge level and attitude score, respectively, about COVID-19, while Umeizudike et al. ${ }^{24}$ reported that only half of the students had a good knowledge level while $94.1 \%$ of the participants showed a positive attitude score. 
Table 5: Perceived mental healthcare needs among participants during COVID-19 pandemic

\begin{tabular}{llll}
\hline & \multicolumn{2}{c}{ Answers N (\%) } & \\
\cline { 2 - 3 } Questions & Yes & No & $p$ \\
\hline $\begin{array}{l}\text { Do you think it would be good } \\
\text { to share your concerns about } \\
\text { the COVID-19 outbreak with } \\
\text { someone? }\end{array}$ & & & 0.121 \\
$\begin{array}{l}\text { Do you think it would be } \\
\text { appropriate to seek mental }\end{array}$ & $186(83)$ & $38(17)$ & 0.410 \\
health help in case of panic due & & & \\
to the pandemic? & & \\
$\begin{array}{l}\text { Do you think it would be helpful } \\
\text { if mental health professionals }\end{array}$ & $204(91.1)$ & $20(8.9)$ & 0.157 \\
help people to cope with the & & \\
$\begin{array}{l}\text { COVID-19 pandemic? } \\
\text { Would you recommend people } \\
\text { who are adversely affected by } \\
\text { the COVID-19 pandemic to seek } \\
\text { mental health assistance? }\end{array}$ & & \\
\hline
\end{tabular}

$p$ values show differences between groups. $\chi^{2}$ test

Table 6: Comparison of knowledge levels, attitude scores, and mental healthcare needs between 4th- and 5th-year students (brackets contain standard deviations)

\begin{tabular}{llrrl}
\hline & & $N$ & \multicolumn{1}{l}{ Mean } & $p$ \\
\hline Total knowledge score & 4th & 134 & $7.22(1.20)$ & 0.061 \\
& 5th & 90 & $7.54(1.33)$ & \\
& Total & 224 & $7.35(1.26)$ & \\
Total attitude score & 4th & 134 & $16.34(2.11)$ & 0.304 \\
& 5th & 90 & $16.64(2.20)$ & \\
& Total & 224 & $16.46(2.15)$ & \\
Total mental healthcare & 4th & 134 & $3.28(0.99)$ & 0.551 \\
need score & & & & \\
& 5th & 90 & $3.36(0.95)$ & \\
& Total & 224 & $3.31(0.97)$ & \\
\hline
\end{tabular}

$p$ values show differences between groups. Independent $t$-test

This inconsistency could be attributed to the fact that we did not enroll 1st-, 2nd-, and 3rd-year students who had not completed theoretical training and lacked practical education regarding clinical practice. Moreover, this could have resulted from differences in the universities' curricula. Our findings indicate the need for training courses, demonstrations, videotaping cases, webinars, and online interactive educational content to improve the knowledge level and attitudes of dental students.

The estimated incubation period for the COVID-19 virus, which originated from bats, is up to 14 days. ${ }^{25}$ In this study, students had good knowledge regarding the incubation period. Moreover, they could determine the infection means, main symptoms, and precautions for preventing infection. This indicates that future dentists can recognize COVID-19 as well as take the necessary precautions in their professional and daily lives and, thus, help prevent viral transmission. Moreover, all the students answered "true" to the question "COVID-19 can cause death," which indicated that they took the illness seriously.
There is still no specific treatment for COVID-19 and it is still managed through supportive therapies. ${ }^{16}$ In this study, $64.3 \%$ of the participants gave correct answers while $27.2 \%$ claimed that there was no COVID-19 treatment. This answer could be attributed to the recovery of nonsymptomatic positive cases without supportive medication. Approximately $6 \%$ of the participants claimed that COVID-19 could be treated by vaccination. Although there are current phase 1 studies, there is no licensed vaccine yet. These answers indicate the need for availability of specific information regarding COVID-19 treatment through online training sessions.

There was no significant difference in the knowledge level between 4th-and 5th-year students. However, a significantly higher number of 5th-year students gave correct answers to the question "Are COVID-19, SARS, and MERS-CoV viruses the same?" than 4thyear students $(p=0.04)$. This demonstrated that 5 th-year students had a higher awareness of communicable diseases.

There are protocols describing infection-control methods and dental treatment procedures for patients with COVID-19. ${ }^{16,17}$ It is important to adhere to these protocols to prevent the spread of the disease. ${ }^{23}$ Most of our participants held a cautious attitude toward COVID-19 similar to the study of Peng et al., ${ }^{26}$ which $73.8 \%$ of the participants reported positive attitudes.

In our study, there was no significant difference between the responses of 4th- and 5th-year students regarding the attitude levels. All students indicated that protective equipment should be worn by dental health workers; moreover, all but one student reported that hands should be cleaned with sanitizers and soap. Consistent with this finding, Khader et al. ${ }^{15}$ reported that most dentists complied with these preventative methods. Moreover, participants of our study reported that dentists should update themselves on new informative guides about COVID-19. This suggests that students are aware of their role in combating the pandemic.

In our study, $86.2 \%$ of the participants stated that only emergency treatments should be applied. In Turkey, only emergency dental procedures were allowed between March and June as recommended by the Turkish Ministry of Health and the Turkish Dental Association, with routine dental procedures being performed from June. The results of this survey conducted in the first pandemic months are consistent with those of the treatment algorithm in Turkey.

In our study, $57.14 \%$ of the students answered "I agree" to the question "I think my dental practice will be insufficient when I graduate or become a 5th year student, and concomitantly the COVID-19 pandemic will affect my medical skills." Moreover, compared with 4th-year students, significantly more 5th-year students answered "disagree" to the first question regarding future concerns. In our study, 5th-year students graduated with only 3 months of incomplete clinical practice. On the other hand, uncertainty regarding when universities open during the next year or whether practical lessons will be held may be the cause of the 4th-year students' concern.

In addition, most of our students worried about their financial situation. Specifically, almost half of the students thought that dental treatment prices would increase after the pandemic. Further, approximately $42 \%$ of the students were anxious about a decrease in job opportunities in dentistry after the pandemic. Almost half of the students were concerned about their professional future after the COVID-19 pandemic. 
In our study, there was a high average score for mental healthcare needs $(3.31 \pm 0.97)$. About $90 \%$ of the students reported a need for psychological help to cope with this epidemic. Additionally, $67.4 \%$ of the students stated that it would be good to share their concerns with someone. Consistent with our findings, a study by Roy et al. ${ }^{19}$ on the Indian population reported that the percentage ratios of affirmative responses to the aforementioned questions were 82.9 and $66.5 \%$, respectively. Similar to dentistry students, the general population acknowledges the need for mental help to overcome panic caused by this pandemic.

These findings suggest that dental students, as future dentists, should update themselves on the latest guides and literature. There is a need for online training sessions on infection control for students frequently using social media. Moreover, lessons should be added to the curriculum to create awareness about the risk of contagious diseases. Finally, there is a need to prepare precaution and management plans for probable future pandemics.

This study has several limitations. First, there was no time restriction for answering the questions. The students may have searched for the correct answers from websites, which may result in bias. Second, since the pandemic continues to rapidly evolve, there will be concomitant changes in guidelines and perceptions. Third, this was a single-center study in Turkey, and the findings may not completely reflect all dental students worldwide.

\section{Conclusion}

Our findings revealed a moderate and high knowledge level and attitude scores, respectively, regarding COVID-19. Future dentists should update their knowledge regarding this pandemic to protect themselves and their patients from this and other outbreaks. From the students' perspective, there is a need for universities and governments to support them and take the required steps for alleviating uncertainties and future concerns. For future dentistry, psychological support programs should be established during infectious disease outbreaks.

\section{Clinical Significance}

There is a need to increase knowledge about COVID-19 among studies through several means, including lessons, and universities and governments should search for new channels for students' concerns and mental healthcare needs.

\section{Acknowledgment}

The authors thank Prof. Dr Hanife Ataoğlu for her contributions to the study. All authors have declared that no financial support was received from any organization.

\section{References}

1. Mahase E. Coronavirus COVID-19 has killed more people than SARS and MERS combined, despite lower case fatality rate. BMJ 2020;18(368):m641. DOI: 10.1136/bmj.m641.

2. The WHO Oral Health website. Available from: https://www.who. int/publications/m/item/weekly-epidemiological-update---24november-2020. Accessed 24 November 2020.

3. The WHO Oral Health website. Available from: https://www.who.int/ publications/i/item/clinical-management-of-covid-19. Accessed 13 Mar 2020.

4. Centers for Disease Control and Prevention website. Available from: https://www.cdc.gov/oralhealth/infectioncontrol/statement-COVID. html. Accessed 27 Mar 2020.
5. Ajilore K, Atakiti I, Onyenankeya K. College students' knowledge, attitudes and adherence to public service announcements on Ebola in Nigeria: suggestions for improving future Ebola prevention education programmes. Health Educ J 2017;76(6):648-660. DOI: 10.1177/0017896917710969.

6. Tachfouti N, Slama K, Berraho M, et al. The impact of knowledge and attitudes on adherence to tuberculosis treatment: a case-control study in a Moroccan region. Pan Afr Med J 2012;12:52.

7. Person B, Sy F, Holton K, et al. National Center for Infectious Diseases/ SARS community outreach team. fear and stigma: the epidemic within the SARS outbreak. Emerg Infect Dis 2004;10(2):358-363. DOI: 10.3201/eid1002.030750.

8. Khosravanifard B, Rakhshan V, Najafi-Salehi L, et al. Tehran dentists' knowledge and attitudes towards hepatitis $B$ and their willingness to treat simulated hepatitis B positive patients. East Mediterr Health J 2014;20(8):498-507. DOI: 10.26719/2014.20.8.498.

9. Halboub ES, Al-Maweri SA, Al-Jamaei AA, et al. Knowledge, attitudes, and practice of infection control among dental students at Sana'a University, Yemen. J Int Oral Health 2015;7(5):15-19.

10. Cleveland JL, Gray SK, Harte JA, et al. Transmission of blood-borne pathogens in US dental health care settings: 2016 update. J Am Dent Assoc 2016;147(9):729-738. DOI: 10.1016/j.adaj.2016.03.020.

11. Sabino-Silva R, Jardim ACG, Siqueira WL. Coronavirus COVID-19 impacts to dentistry and potential salivary diagnosis. Clin Oral Investig 2020;24(4):1619-1621. DOI: 10.1007/s00784-020-03248-x.

12. Chen $Y$, Tong $X$, Wang J, et al. High SARS-CoV-2 antibody prevalence among healthcare workers exposed to COVID-19 patients. J Infect 2020;81(3):420-426. DOI: 10.1016/j.jinf.2020.05.067.

13. Asaad A, El-Sokkary R, Alzamanan M, et al. Knowledge and attitudes towards middle east respiratory syndrome-coronavirus (MERS-CoV) among health care workers in south-western Saudi Arabia. East Mediterr Health J 2020;26(4):435-442. DOI: 10.26719/emhj.19.079.

14. Hawryluck L, Gold WL, Robinson S, et al. SARS control and psychological effects of quarantine, Toronto, Canada. Emerg Infect Dis 2004;10(7):1206-1212. DOI: 10.3201/eid1007.030703.

15. Khader Y, Al Nsour M, Al-Batayneh OB, et al. Dentists' awareness, perception, and attitude regarding COVID-19 and infection control: cross-sectional study among jordanian dentists. JMIR Public Health Surveill 2020;6(2):e18798. DOI: 10.2196/18798.

16. Meng L, Hua F, Bian Z. Coronavirus disease 2019 (COVID-19): emerging and future challenges for dental and oral medicine. J Dent Res 2020;99(5):481-487. DOI: 10.1177/0022034520914246.

17. Samaranayake $L P$, Peiris $M$. Severe acute respiratory syndrome and dentistry: a retrospective view. J Am Dent Assoc 2004;135(9):12921302. DOI: 10.14219/jada.archive.2004.0405.

18. Althomairy SA, Baseer MA, Assery M, et al. Knowledge and attitude of dental health professionals about middle east respiratory syndrome in Saudi Arabia. J Int Soc Prev Community Dent 2018;8(2):137-144. DOI: 10.4103/jispcd.JISPCD_9_18.

19. Roy D, Tripathy S, Kar SK, et al. Study of knowledge, attitude, anxiety \& perceived mental healthcare need in Indian population during COVID-19 pandemic. Asian J Psychiatr 2020;51:102083. DOI: 10.1016/j. ajp.2020.102083.

20. Khan MU, Shah S, Ahmad A, et al. Knowledge and attitude of healthcare workers about middle east respiratory syndrome in multispecialty hospitals of Qassim, Saudi Arabia. BMC Public Health 2014;14(1):1281. DOI: 10.1186/1471-2458-14-1281.

21. Odacı H. Risk-taking behavior and academic self-efficacy as variables accounting for problematic internet use in adolescent university students. Child Youth Serv Rev 2013;35(1):183-187. DOI: 10.1016/j. childyouth.2012.09.011.

22. The WHO Oral Health website. Available from: https://covid19.who. int/. Accessed 29 November 2020.

23. Esmaeelinejad M, Mirmohammadkhani M, Naghipour $A$, et al. Knowledge and attitudes of Iranian dental students regarding infection control during the COVID-19 pandemic. Braz Oral Res 2020;34:e121. DOI: 10.1590/1807-3107bor-2020.vol34.0121. 
24. Umeizudike KA, Isiekwe IG, Fadeju AD, et al. Nigerian undergraduate dental students' knowledge, perception, and attitude to COVID-19 and infection control practices. J Dent Educ 2020. 21. DOI: 10.1002/ jdd.12423.

25. Duruk G, Gümüşboğa ZŞ, Çolak C. Investigation of Turkish dentists' clinical attitudes and behaviors towards the COVID-19 pandemic: a survey study. Braz Oral Res 2020;34:e054. DOI: 10.1590/1807-3107bor2020.vol34.0054.

26. Peng Y, Pei C, Zheng Y, et al. A cross-sectional survey of knowledge, attitude and practice associated with COVID-19 among undergraduate students in China. BMC Public Health 2020;20(1):1292. DOI: 10.1186/ s12889-020-09392-z. 